\title{
IMPORTANCIA DE LA ACTIVIDAD TEXTIL EN EL PROCESO DE INDUSTRIALIZACIÓN: INDUSTRIA TEXTIL CUSQUEÑA: ENTRE LA MEMORIA Y EL OLVIDO
}

\author{
Importance of textile activity in the process of industrialización: textile industry from Cusco: \\ between memory and oblivion
}

\author{
Miguel Eduardo Velarde Oliart ${ }^{1, \risingdotseq-}$ \\ 1 Universidad Andina del Cusco, Cusco, Perú.
}

"Una cabeza sin memoria, es como una fortaleza sin guarnición"

Napoleón Bonaparte

\begin{abstract}
Citar como: Velarde, M. (2018). Importancia de la actividad textil en el proceso de industrialización: industria textil cusqueña: entre la memoria y el olvido (carta al editor). Rev Yachay, 7(1), 490-496.
\end{abstract}

Recibido: 16-09-2018; Aceptado 07-12-2018

\begin{abstract}
Sr Editor
Puede sorprender a muchos jóvenes cusqueños el mencionar sobre la "industria textil cusqueña”, quienes se preguntarán ¿Qué industria textil cusqueña? ¿Dónde está? En cambio, muchos adultos se acuerdan de ella, algunos con la nostalgia de un tiempo pasado y desperdiciado; mientras que otros, la recuerdan con ciertas dudas y algo de desprecio.

Haciendo un poco de memoria. Las primeras fábricas textiles modernas del Perú republicano fueron: La fábrica de hilados y tejidos de algodón de Los Tres Amigos, fundada en Lima en 1848; la fábrica de hilados y tejidos de seda de Sarratea y Navarrete, fundada en la Capital hacia el año de 1849; la fábrica de hilados y tejidos de lana de Lucre fundada en Cusco en 1861; y el mismo año, se fundó la fábrica de hilados y tejidos de lana de Urcón en Ancash. Estas fábricas corresponden a un proceso de industrialización sin revolución industrial, periodo en que existió un crecimiento económico sin precedentes a consecuencia de la exportación del guano de islas, periodo en que la población del litoral era extremadamente adepta a las importaciones de manufacturas; mientras que la sierra, se encontraba alejada de beneficiarse del sistema mercantil de la costa. Las fábricas de tejidos de Lima, desaparecieron hacia la década de 1860 , afectadas por el anti-industrialismo limeño, que enfatizaba el libre comercio y no la industrialización. Mientras tanto, las dos fábricas serranas se mantuvieron en funcionamiento, debido a su economía de resistencia, y a sus mercados pequeños, dispersos y aislados por las montañas, que alejaba el ánimo de comercio para las importaciones de tejidos.

Hacia 1871, fue fundada la moderna fábrica de tejidos de algodón de Vitarte, unida al ferrocarril Central de Lima. Esta fábrica, además de haber sido el núcleo de expansión urbana e industrial en Lima, dio inicio a la sustitución de importaciones en el litoral, por lo que es considerada ésta, como el inicio del surgimiento de la industria moderna de tejidos de algodón.

Posteriormente se desarrolló un segundo proceso de industrialización, este a consecuencia del colapso económico ocasionado por la Guerra del Pacífico, que alejó a las importaciones, y que dio margen a la producción nacional como única forma de abastecer a la empobrecida nación, al tiempo que fue ganando importancia la exportación de las lanas andinas. Hacia 1919, en el Perú existían quince fábricas de tejidos, nueve en Lima, una en Arequipa, una en Ica, y cuatro en Cusco. Estas eran: en Lima: Vitarte Cotton Mill, Inca Cotton Mill, El Progreso, La Unión, Santa Catalina, La Victoria, San Jacinto, La Bellota y la Del Pacífico; en Arequipa: La Industrial; en Ica: Malatesta; y en Cusco: Lucre, Maranganí, De Urcos y Huáscar, a la que se sumó La Estrella en 1928, con lo que la industria textil en Cusco se veía prometedora, dando Cusco tempranamente el paso hacia la industrialización... sin revolución industrial.

Hoy en día, cuando recorres la antigua infraestructura de la fábrica de Lucre, con sus maquinarias detenidas en el tiempo, las que son conservadas para el futuro museo de sitio como puesta en valor de este patrimonio industrial, trae muchas preguntas a la mente. ¿Cómo
\end{abstract}


es que se instaló una fábrica como esta en aquel espacio geográfico? siendo el lugar más idóneo la costa central. ¿Qué factores habrían posibilitado la instalación de la fábrica, y que dificultades había atravesado para hacerlo?, son algunas de las interrogantes que los visitantes se plantean, siendo esta otra la más interesante en la actualidad para los visitantes cusqueños y nacionales, y a la cual intentaré dar algunas respuestas... si esta fábrica se instaló hacia el año de 1861, y hacia 1930 en Cusco existían 5 fábricas textiles, ¿Porque hoy solo funciona una o dos fábricas? ¿No debería haber en el Cusco por lo menos 15 fábricas textiles en la actualidad, ya que en la región existen las materias primas?

\section{Desarrollo y progreso material}

En nuestro medio, la industria no es muy bien estimada, pues es percibida como un fenómeno importado y por ello foráneo, y por lo tanto, guarda poca relación cultural con la sierra andina, vector al que se le suma la mentalidad anti industrial. Este anti industrialismo, agregado al anti capitalismo y al centralismo, son agentes que impiden el desarrollo material de la sierra sur, pese al impulso económico existente.

Ante ello, es imprescindible: crear y/o fortalecer la identidad cultural hacia el desarrollo y el progreso material, mediante la valoración del trabajo, de la producción y de la industria, identidad que, una vez fortalecida, será el medio para que Cusco pueda dar valor a sus riquezas naturales mediante la aplicación de las riquezas del conocimiento. Esto, sin dejar de lado, las riquezas tangibles e intangibles existentes.

\section{Sistemas de producción ¿fábricas en el Perú Prehispánico?}

En Inglaterra, para antes de la Revolución Industrial, los tejidos se elaboraban en las viviendas, siendo una actividad complementaria a la agricultura, sistema de producción denominado putting out system. Con el advenimiento de la Revolución Industrial, las máquinas al igual que el personal calificado, se concentraron bajo infraestructuras fabriles al mando de élites industriales, desarrollando el sistema productivo denominado factory system.

En lo que respecta al Perú prehispánico, se aprecia desde tiempos de la cultura moche, la existencia de infraestructuras que albergaban decenas y hasta centenas de tejedores, los que operaban rudimentarios telares, bajo el control de élites administrativas-religiosas. Así mismo, en el imperio Inca existieron grupos especializados en la labor textil, entre ellos los cumbicamayoc y las acllas, que realizaban finos tejidos, grupos que se congregaban por cientos y hasta miles al interior de infraestructuras destinadas para dicho fin.

Esto mostraría que en el Perú prehispánico, además de desarrollarse sistemas de producción similares al putting out system, se desarrollaba algo similar al factory system, aclarando que existían diferencias contextuales para usar dichos términos, como la conceptualización de propiedad privada y del crédito, de capital y capitalismo, de liberalismo y librecambismo; sin embargo, es interesante ver como se desarrollaba la producción a gran escala en el prehispánico ante la ausencia de estos componentes.

\section{Obrajes. Protoindustrias}

La existencia de espacios con infraestructuras donde se albergaban cierta cantidad de tejedores con rústicos telares en el prehispánico, habría sido una condición que captó la atención de los españoles, quienes habrían visto cierta similitud con la industria textil desarrollada en España; ya que, en aquel país, existían fábricas con cientos de trabajadores que operaban máquinas de tecnología medieval. Estos factores, posiblemente, habrían determinado que los colonos fundaran sus obrajes sobre los cimientos de la ingeniería de la industria textil prehispánica; motivo por el cual, en el Perú virreinal, se fundaron varios cientos de obrajes sobre todo en la sierra sur (Cusco, Puno y Ayacucho) donde se aprovechaba la lana, y en la costa norte (Quito) donde se empleaba el algodón.

La industria textil colonial, surgió ante la existencia de los diversos componentes industriales como: materias primas, mano de obra calificada, mercados, entre otros, siendo una industria muy arraigada culturalmente, y muy prometedora económicamente, motivo por el cual, la Corona española hizo los esfuerzos supremos para doblegarla, con la finalidad de evitar una independencia económica y política de sus colonias. Esta industria textil, fue la base embrionaria de las fábricas rurales instaladas en Cusco, sobre todo en lo que a la fábrica de Lucre se refiere.

Es por ello que, la industria moderna o industrialismo, si bien nació en Occidente, posee cierta similitud cultural con la sierra sur en lo que se refiere a producción, sin embargo, es necesario tomar temas de readaptación e introducción de pensamientos, lo que se puede conseguir con la puesta en valor de la identidad cultural hacia el desarrollo y el progreso material.

\section{Revolución Industrial Europea}

La Revolución industrial europea, fue un proceso gradual, lento e indetenible, proceso que inicialmente era casi mudo, y que fue cambiando gradualmente los sistemas gubernamentales y la mentalidad de los europeos occidentales, hasta que hacia finales del siglo XVIII e inicios del siglo XIX, hizo un estallido estruendoso en medio de revoluciones científicas, tecnológicas, políticas, sociales y culturales. Hacia este periodo, fue emancipado hacia la Revolución Industrial, el Estado que fomentara la industria con buenas y sabias leyes; el sector privado que invirtiera los capitales requeridos; y el pueblo libre habría de trabajar en aquellas industrias, mejorando su estilo de vida y conllevando al crecimiento económico.

La Revolución de la industria agropecuaria, fue la primera etapa de la Revolución industrial inglesa. El mejoramiento de la tecnificación de esta industria, dejó sin actividad agropecuaria a miles de campesinos, los que, en búsqueda de trabajo, migraron en grandes masas hacia los nuevos centros urbanos que surgían alrededor de las nuevas fábricas, conformando ciudades enteras. 
Las nuevas tecnologías surgidas en la Revolución Industrial, no fueron fruto de licenciados universitarios ni de científicos de renombre, fueron inventados por productores, muchos de los cuales desarrollaban sus actividades en la clandestinidad, pues eran acosados y amenazados por los gremios, los que defendían el status quo. Es por ello que, muchas fábricas manufactureras fueron instaladas en zonas rurales, donde no les alcanzaban las leyes de los gremios, conformando sistemas extralegales, sistemas que, una vez arraigados, no le quedó al Estado más que darles forma y legalizarlos. Así, las leyes emanadas del Estado, fueron inspiradas y adaptadas por los cambios contextuales, incitados por industriales, científicos y humanistas, lo que hizo de la Revolución industrial europea un proceso indetenible para ellos.

La Revolución Industrial iniciada a finales del siglo XVIII, empezó con el establecimiento de 3 inventos:

La máquina de vapor, empleada para mover otras máquinas, y sobre todo, para impulsar los medios de transporte.

Los otros dos inventos fueron: la máquina de hilar y el telar mecánico, ambos pertenecientes a la industria textil, máquinas cuyas continuas innovaciones tecnológicas abrieron camino a la industria moderna, al maquinismo y a la automatización, marcando estas innovaciones el comienzo de la Revolución Industrial. Así mismo, la incorporación de las tarjetas perforadas del telar Jacquard (Francia), es el paradigma de la primera máquina computacional.

Estos inventos, colocaron a la industria textil inglesa, como la más importante de aquel periodo, industria que permitió a Inglaterra, invadir con mercancías y capitales a varios países hispanoamericanos, manufacturas que ingresaban legal e ilegalmente. El ingreso de estas mercancías al Perú colonial; así como, las rebeliones y otros acontecimientos, ocasionaron el declive de la industria textil colonial desarrollada en los obrajes, que operaban con máquinas de tecnología medieval (que eran la base tecnológica de las máquinas de la Revolución Industrial). Una vez conseguida la independencia del Perú, estas importaciones continuaron amenazando, no solo al establecimiento de nuevas y modernas fábricas textiles; sino también, amenazaban la independencia económica y, por ende, la independencia política del Perú.

\section{Perú. Industrialización sin revolución industrial}

En contraste, el panorama del Perú del siglo XIX era diferente. El país salía del aislacionismo provocado, de la violencia y del empobrecimiento a consecuencia de las guerras de independencia, y para ganar dinero fácil, el gobierno abrió los puertos al libre comercio, siendo las ciudades del litoral inundadas por mercancías procedentes de la Revolución industrial europea. Ante ello, las antiguas fábricas textiles coloniales terminaron por sucumbir, entrando el país en un periodo en que la economía era vista en función de exportación de materias primas y en importación de manufacturas, por lo que el Estado y sus gobiernos, no apoyaron el proceso de industrialización de aquel entonces, al cual veían en algunos casos como un obstáculo en torno a la perspectiva de obtener recursos económicos provenientes de las importaciones. Por estos motivos, los únicos que fomentaban la industria manufacturera peruana, e invertían en ella, era cierto estrato de elitistas que veían que el crecimiento económico del Perú estaba en función a satisfacer las necesidades de la nación; punto de vista muy diferente al de los elitistas dedicados a la agro exportación.

La industria del agro exportación peruana desarrollada en el litoral, es otra antítesis de la Revolución Industrial. Esta nació décadas después de que el Perú consiguiera su independencia. Esta industria si recibió fomento del Estado y créditos extranjeros, cuyos productos eran exportados para alimentar a otras naciones y llenar los bolsillos de aquellas élites; a cambio de la importación de todo tipo de productos... desde los más básicos (como el trigo) hasta los más suntuosos, quedando la alimentación de la nación relegada por meros factores económicos a corto plazo. En contraste, la alimentación per cápita terminó siendo más costosa para el común habitante de la costa, estando en continua dependencia de la producción extranjera.

Otra antítesis de la Revolución Industrial eran los mercados cautivos. La conformación socio demográfica del Perú antes de la Reforma Agraria, era otro obstáculo para la Revolución industrial peruana. El tercer elemento que debería emanciparse hacia la Revolución Industrial, estaba emancipado parcialmente. Un gran segmento de la población, es decir, el campesinado, se encontraba cautiva al interior de las haciendas, y de las comunidades campesinas. Los campesinos de la costa, se encontraban más expuestos a los cambios económicos, políticos y sociales, lo que posiblemente ha contribuido a que, desde la década de 1980 en el litoral se desarrolle la Revolución industrial, población a la que se fue integrando mentalmente los migrantes del interior del país.

\section{Revolución industrial en el litoral peruano}

De acuerdo al economista Hernando de Soto en El Otro Sendero, el Perú empezó a desarrollar una Revolución Industrial recién en la década de 1980, punto de vista que lo sustenta con un cuidadoso estudio de la Revolución industrial europea y sus similitudes con el proceso de industrialización del Perú en esa década, como son: la migración de campesinos a las ciudades, sobre todo de sierra a costa, la invasión de tierras y el proceso de reconocimiento legal, la instalación de fábricas y de negocios al margen de la ley, la conversión de lo extralegal en legal, entre otras características.

Desde este entender, se podría decir que hoy en día, el Estado, el sector privado y la población se están emancipando hacia la adopción de la Revolución Industrial; sin embargo, este proceso bien podría estar limitado, definido y conceptualizado para el litoral; sin embrago, en muchas regiones del interior país como en Cusco, no ha iniciado.

Revolución industrial en el sur andino. Un paso a dar 
En la sierra sur, el panorama siempre fue diferente. La Reforma agraria hizo que el campesinado pasara del cautiverio de hacienda, al cautiverio de comunidad campesina, este último, autoimpuesto. Este cautiverio tiene que ver con sentimientos de resistencia hacia todo lo foráneo, de aislacionismo, de anti-industrialismo y de anti-capitalismo.

Por ello, un gran segmento de la población de la sierra sur, no pretende emanciparse hacia una Revolución industrial (y es posible que muchos den por sentado que esta ya sucedió), pensamiento que es muy diferente a obtener dinero. Todos queremos dinero... todos queremos trabajo... todos queremos un mejor estilo de vida... pero, un gran segmento, no están dispuestos a contribuir con el progreso y la industria manufacturera... creen que los inversionistas son los que deben poner las fábricas y mover la industria, por lo que en equilibrio han de oponerse a ellas (capitalistas versus proletariado), sin tomar en cuenta tanto el origen de los inversionistas (cusqueños, peruanos o extranjeros), ni el tipo de industria (de enclave o de encadenamiento, extractiva o manufacturera), por ende, no tienen una perspectiva válida de los beneficios y problemas que estas traen. Por ello, en Cusco hay un lema sarcástico que dice: "Que hay para oponerme". Así, la mayor parte de la población deja de lado la verdadera importancia que posee ante el proceso de industrialización. ¿No es esto una muestra de complejo de inferioridad, por no creerse sujetos de cambio?

Por ejemplo, ante la inversión de capitales en zonas rurales, sean dichas inversiones de cusqueños, de peruanos o de extranjeros, muchas comunidades campesinas dirigidas por sus élites extralegales, tras oponerse, abren una brecha al dialogo para la inversión de capitales, no sin antes haber pedido dinero por anticipado. Es decir, surge la oposición ante la inversión en industria, no por la preservación cultural y ambiental que tanto proclaman, sino más bien, para causar presión sobre los inversionistas y así obtener dinero.

Para hacer un análisis rápido de este asunto. Por ejemplo, cuando un cusqueño va a invertir en industria o un emprendimiento de relativa magnitud en una zona rural del Cusco, como, poner en marcha una mini central hidroeléctrica, la comunidad campesina, encabezada por sus élites extralegales, se apresuran a oponerse a ella, con motivo del uso del agua, entre otros; por otro lado, dichas élites de forma indirecta entablan conversaciones con dichos inversionistas, los que sugieren la entrega de dinero para solucionar los problemas. Por un lado, ¿esto no es una forma de intimidación y de extorción hacia el inversionista cusqueño? Por otro lado, es preciso tener en cuenta que: los inversionistas cusqueños, son capitalistas en formación, tienen capitales tan limitados, que solo poseen los recursos suficientes para poner en marcha cierto tipo de emprendimientos; e incluso, muchas veces, sus recursos económicos son en la práctica insuficiente; factores a los que se añade la falta de fomento y de protección del Estado (factor diferente al proteccionismo), y a los vaivenes económicos y políticos del país. Ante esto, ¿cuáles son las consecuencias que acarrean la oposición y el saqueo a dichas inversiones? Lo más probable es que dicho emprendimiento se quede a medias y no produzca nada, perdiendo capitales el inversionista, y manteniéndose el status quo en la zona donde se desarrollaba dicha inversión; es decir, no se benefició nadie, más al contrario. A la larga, estos fenómenos sociales socaban la actitud de liderazgo, de emprendimiento y de industria, justo los factores requeridos para industrializar Cusco. En pocas palabras, la misma población cusqueña reduce y neutraliza sus posibilidades de desarrollo económico. Ante este panorama es bueno preguntar ¿Qué sucederá cuando tu o tus hijos deseen emprender algún tipo de industria en Cusco? ¿Si son emprendedores, tendrán que irse del Cusco para lograr sus objetivos? ¿Es la forma como Cusco trata a sus hijos?

Algunos partidarios de la oposición y de las dádivas de dinero, pueden argumentar: bueno, por aquí no vemos muchos inversionistas cusqueños, y los que existen son tan pocos, que no vale la pena pensar en ellos, pues ellos nunca realizarán algún cambio. Pero los inversionistas extranjeros sí que tienen dinero, sino como harían tremendas fábricas e instalaciones como las dedicadas a la extracción de minerales. A ellos si hay que oponerse y pedirles un buen billete... sino, que queda para nosotros: el pueblo.

Es cierto. Dichas corporaciones que invierten en minería tienen enormes recursos, tanto económicos como tecnológicos y políticos. Sin embargo, dichas entidades pese a que poseen grandes recursos económicos, cuando realizan un emprendimiento, limitan sus inversiones a un óptimo, y si la inversión sale de sus parámetros, significa que no es una buena inversión. En pocas palabras, el dinero que distribuyen a los agitadores, está dentro de su presupuesto, pero ¿A qué costo? ¿Acaso este panorama no promueve la corrupción?, pues si estos gastos están presupuestados, eso significa dos cosas: primero, ese dinero saldrá de las inversiones en obras sociales y de preservación ambiental, que beneficiarían a la colectividad, y no a un grupo; o segundo, dichas empresas, ante esta coyuntura, presupuestan recursos para nutrir la corrupción que va desde la población campesina, pasando por sus élites extralegales hasta las autoridades legales; así, la corrupción, termina siendo más económica y rentable que invertir en programas sociales y tecnológicos, gestando diversas brechas entre inversionistas, población y Estado. Estos panoramas en realidad no son nada alentadores para la industrialización cusqueña. A esto hay que agregar que, dichas inversiones, al poseer recursos políticos, no dejan un solo dólar en el Perú sin aval del Estado, por ello, el Estado protege estas inversiones; además de fomentarlas con la exoneración de ciertos tributos a cambio de regalías; sumándose a todo esto, la inexistencia de políticas estatales que, mediante diversas estrategias, eviten la salida de los capitales generados por estas inversiones hacia el exterior, lo que conlleva a que estas inversiones sean fuente de un crecimiento económico insostenido, ya que no generan economías de encadenamiento, o en su defecto, lo hacen de manera muy limitada.

Estos fenómenos no se limitan a las zonas rurales cusqueñas, pues a la vez estos fueron nutridos por corrientes ideológicas de ultramar, las que ingresaron por las zonas urbanas. Por ello no es raro que, profesionales con laptop y i-phone en mano, que están continuamente buscando trabajos mejores remunerados, incluso en horarios de oficina, se opongan al proceso de industrialización cuando ocupan 
puestos del Estado, por lo que el anti-industrialismo y el anti-capitalismo no solo es una característica de la población rural y urbana, sino también, está arraigada en la mentalidad de burócratas, oficinistas y autoridades.

En países liberalistas y capitalistas (como EEUU y países de Europa occidental) el Estado está para servir a su ciudadanía, convirtiendo a sus autoridades en servidores. A comparación, en países en vías de desarrollo como el nuestro, la ciudadanía está para servir al Estado, por lo que no es raro que presidentes elegidos democráticamente, actúen de forma por demás presuntuosa y déspota, realizando cambios y modificando leyes como si fuera el país de su propiedad, desvirtuando la democracia que promulgan. A esto se añade que, las políticas económicas giran en torno a la distribución de las riquezas, y no en torno a la generación de las mismas.

Por estos y otros motivos, la industrialización del Cusco es una lucha quijotesca, en la que hay que enfrentar el invisible viento del antiindustrialismo, del anti-capitalismo, del centralismo, del mercantilismo y otros vectores más. No basta con que inversionistas arriesguen millones de dólares en industrializar Cusco, no basta con que el Estado invierta algunos recursos para aparentar el tan ansiado fomento hacia la industria serrana, no basta con el ánimo hacia el trabajo y hacia la riqueza que posee la población... faltan industrias, y para ello, es imprescindible la emancipación de los poderes del Estado, de la iniciativa privada y de la población hacia la industrialización; siendo este el primer paso para contrarrestar los nocivos efectos del centralismo, del capitalismo y del imperialismo.

No se trata de desarrollar el sueño americano, sino, de construir una mejor realidad para los cusqueños y la sierra andina.

\section{¿El capitalismo ha fracasado en la Sierra Sur!}

Algunos opositores a la industria dicen... el capitalismo ha fracasado, sobre todo en la sierra sur y en Cusco en particular. Las antiguas fábricas serranas fracasaron, los antiguos hacendados fracasaron, y fue un fracaso el desarrollo social en aquellos tiempos, que no nos condujo a la industrialización y al desarrollo de riquezas, más por el contrario, nos hizo pobres y miserables. Hoy en día, el capitalismo no hace más que sacarnos el dinero del bolsillo, pues casi todo lo que compramos no es producido en esta región. Ante la inversión de grandes capitales y flujos de dinero, el Cusco no se industrializa, no hay industriales en Cusco, por ello, el capitalismo fracasó y fracasa hoy en día, impide el desarrollo de emprendimientos en la región, y solo fomenta aquellas actividades que extraen nuestras riquezas naturales, dejando tras de sí contaminación ambiental y pobreza social.

Esto puede ser cierto en parte, pero también, este pensamiento tiene que ver con el círculo vicioso que nos mantiene en el tormentoso status quo.

Como sostuvo Hernando de Soto, la Revolución Industrial inició en el Perú en la década de 1980, justo después de la Reforma agraria, fenómeno presentado sobre todo en el litoral peruano. De este entender, hasta antes de la década de 1980, en lo que se refiere a los elitistas adinerados peruanos, estos eran proto-capitalistas y un pequeño segmento capitalista, quienes se desenvolvían en un sistema mercantilista, y no capitalista; sin embargo, los gobiernos se afanaban en mostrar al Perú como capitalista, esto con el fin de mostrar al país a la altura para hacer grandes negocios con otros países... fenómeno recurrente en muchas políticas peruanas, que tratan de poner al país a la altura, sin antes haber escalado la ladera.

Hoy en día, es cierto que el país está en vías de un sistema capitalista, pero está en proceso, pues si por ejemplo, pusiéramos un sistema que mapee al Perú sobre el sistema capitalista, solo se verían algunas regiones y otras no; y particularmente en Cusco, se verían las ciudades y una que otra zonas rurales, ya que gran parte de terrenos en uso, no están reconocidas legalmente por varios motivos, factor que dificulta o encarece la capitalización de la propiedad privada mediante financiamientos; siendo el reconocimiento y la defensa legal de la propiedad privada, el punto de partida, y hasta podría decirse, la esencia del capitalismo.

Por ello, algunas regiones como el Cusco, están a la sombra, o mejor dicho, a la periferia del capitalismo, no solo por la falta de reconocimiento y la defensa legal de la propiedad privada, sino también por nuestro nivel de consumo, que es mucho mayor que el nivel de producción, lo que significa que, participamos en el capitalismo como meros consumidores, no aportando a la producción y al capitalismo en sí; más al contrario, el capitalismo termina absorbiendo tanto recursos naturales como capitales gestado; estando el capitalismo regional seriamente vulnerado por todos estos fenómenos, haciéndolo casi inexistente, siendo el capitalismo regional, el único sistema que, una vez arraigado y engrosado, permitirá que participemos y gocemos en parte, de los beneficios del capitalismo global.

Es necesario resaltar que, el capitalismo, como sistema económico, no es perfecto y justo; sin embargo, es el mejor sistema económico desarrollado hasta la actualidad. Así mismo, los sistemas económicos no son estáticos, más bien son dinámicos, es por eso que con el tiempo tienden a evolucionar; y el aporte de países en vías de desarrollo, puede contribuir a mejorarla.

\section{Referencia bibliografia}

Comín Comín, Francisco.

2011 Historia Económica Mundial: De los orígenes a la actualidad. Primera edición 2011, Cuarta reimpresión 2014. Alianza Editorial; ed. Madrid, España. ISBN: 978-84-206-5476-8.

De Soto, Hernando.

Rev. Yachay volumen (7) Número (1), enero-diciembre 2018 
Escandell-Tur, Neus

1997 Producción y comercialización de tejidos coloniales. Los obrajes y los chorrillos del Cusco. 1570 - 1820. Centro Bartolomé de las Casas. Cusco, Perú: Talleres gráficos CBC. ISBN 84-8387-045-2.

Espinoza Soriano, Waldemar

2012 Los Incas. Economía, sociedad, y estado en la era del Tawantinsuyo. Edición de octubre de 2012. La Paz, Bolivia. Ediciones Inkamaru.

2010 Economía política y doméstica del Tahuantinsuyo. En Compendio de la historia económica del Perú: Tomo 1: Economía Pre hispánica. Segunda edición. Contreras, Carlos; ed. Lima, Perú. IEP; BCRP. ISBN: 978-9972-51223-0.

Glave, Luis Miguel

2009 Propiedad de la tierra, agricultura y comercio: 1570-1700. En Compendio de la historia económica del Perú: Tomo 2: Economía del Periodo Colonial Temprano. IEP; BCRP. Carlos Contreras, Editor. Primera edición. Lima, Perú. ISBN 978-9972-51-254-4.

Mason, Paul.

2016 Postcapitalismo. Primera edición. Espasa Libros, S.L.U. (Paidos); ed. España. ISBN: 978-84-493-3187-9.

Murra, John V.

1999 La organización económica del estado inca. Traducción: Daniel R. Wagner. Sexta edición en español. México. Siglo veintiuno editores.

2002 El mundo andino: población, medio ambiente y economía. Pontificia Universidad Católica del Perú. Primera edición. Perú: IEP Ediciones. ISBN 9972-51-072-7. ISSN 1019-4591.

Noejovich, Héctor Omar

2009 La transición del sistema prehispánico al sistema económico colonial. En: Compendio de la historia económica del Perú: Tomo 2: Economía del Periodo Colonial Temprano. IEP; BCRP. Carlos Contreras, Editor. Primera edición. Lima, Perú. ISBN 978-9972-51-254-4.

Quiroz Chueca, Francisco

2010 Industria urbana y rural en el Perú colonial tardío. En: Compendio de la historia económica del Perú. Tomo 3. Economía del Periodo Colonial Tardío. IEP; BCRP. Carlos Contreras, Editor. Primera edición. Lima, Perú. ISBN 978-9972-51-270-4.

Salas Olivari, Miriam

2009 Manufacturas y precios en el Perú colonial. En: Compendio de la historia económica del Perú: Tomo 2: Economía del Periodo Colonial Temprano. IEP; BCRP. Carlos Contreras, Editor. Primera edición. Lima, Perú. ISBN 978-9972-51-254-4.

Salazar Soler, Carmen

2009 Minería y moneda en la época colonial temprana. En Compendio de la historia económica del Perú: Tomo 2: Economía del Periodo Colonial Temprano. IEP; BCRP. Carlos Contreras, Editor. Primera edición. Lima, Perú. ISBN 978-9972-51-254-4.

Salinas Sánchez, Alejandro 
Santillana, Julián I.

2010 Economía prehispánica en el área andina. En Compendio de la historia económica del Perú: Tomo 1: Economía Pre hispánica. Segunda edición. Contreras, Carlos; ed. Lima, Perú. IEP; BCRP. ISBN: 978-9972-51-223-0. ISSN 2071-4246.

Velarde Oliart, Miguel Eduardo.

2018 Fábrica de Hilados y Tejidos de Lana Lucre: Textiles en la Historia. Primera edición. Universidad Andina del Cusco; ed. Cusco, Perú. ISBN: 978-612-47281-9-8.
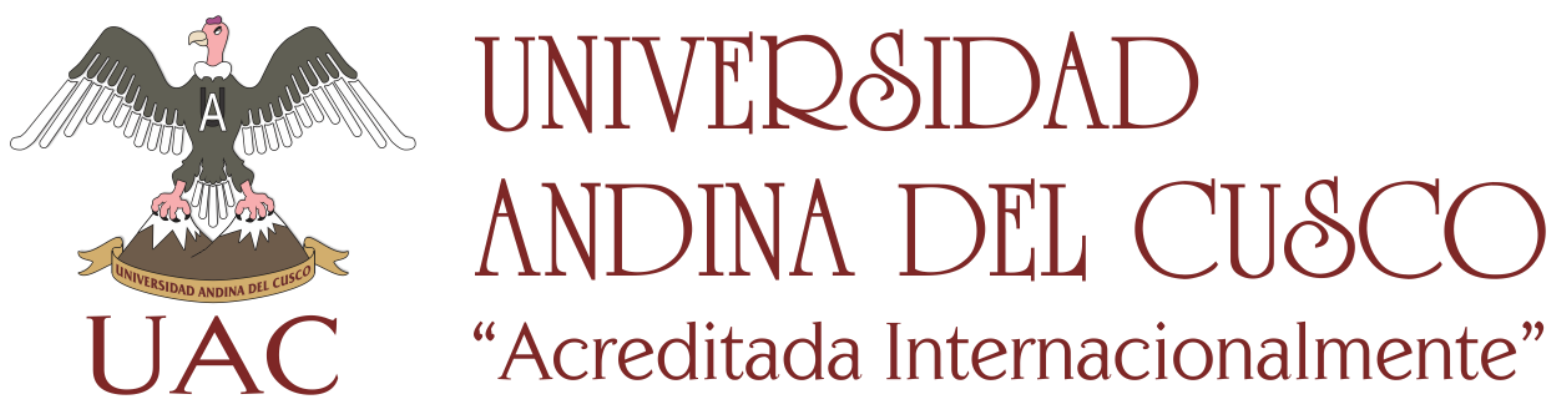